\title{
Losers could still be winners in ESA space competition
}

Paris. The Space Science Advisory Committee of the European Space Agency (ESA) last week selected four out of seven space science proposals in the semifinal of a competition that will eventually lead to the selection of one as a 'medium-sized' science mission to be sent into space in 2003.

But, spoilt for choice, ESA did not reject the remaining proposals. Two will be considered for upgrading to 'cornerstone' missions, and the other will be reviewed internally to see if it can be combined with hardware from other planned missions. The advisory committee's recommendations will probably be endorsed by ESA's Science Program Committee in June.

The four finalists are:

- MORO, a lunar orbiting observatory aimed at studying the Moon's surface and interior;

- INTERMARSNET, a network of 7.5-kg stations to be sent to the surface of Mars to study its atmosphere, surface and internal structure;

- COBRAS/SAMBA, a satellite to measure cosmic background radiation, which its promoters claim has ten times more sensitivity and 50 times greater resolution than NASA's COBE satellite; and

- STEP, Satellite Test of the Equivalence Principle, one of last year's finalists, which will carry out several experiments in basic physics.

ESA will furnish each of the four finalists with ECU800,000 (US\$900,000) to finish a further year's study, including industrial development. The final winner will emerge following a similar competition next year. ESA will budget ECU345 million to build, launch and operate what will be its third medium-sized mission. The losers can run again in future years.

ESA also decided to refer the STARS proposal for a stellar physics mission to an internal study, without industrial involvement, to see whether its cost could be reduced by using a 'bus' developed for either the XMM or Rosetta mission.

The advisory committee also proposed upgrading two of the seven proposed projects - LISA and Mercury Orbiter - to "cornerstone' missions. The budget for the latter missions is around double that of medium missions, and better suited to both proposals, says ESA. "They were very good, but very expensive."

LISA (Laser Interferometer Space Antenna) would search for gravitational waves from black holes, neutron stars, white dwarfs, and the Big Bang. The Mercury Orbiter satellite would have arrived at Mercury in 2008 and studied the planet's geology and surface composition.Declan Butler

\section{CSIRO loses out in switch to 'strategic' research}

Sydney. Paul Keating, the Australian prime minister, announced last week that his government intends to spend A $\$ 60$ million (US $\$ 84$ million) on creating seven new strategic research centres, and another $\mathrm{A} \$ 118$ million on a string of 'technology diffusion' centres across the country.

At the same time, however, the government plans to cut $\mathrm{A} \$ 20$ million from the budget of the Commonwealth Scientific and Industrial Research Organisation (CSIRO), the country's largest research organization, which last year was A\$670 million. The cut is likely to result in the loss of between 200 and 300 staff.

Ironically, the

\section{IMAGE UNAVAILABLE FOR COPYRIGHT REASONS} decisions were announced to parliament as part of a white paper (policy document) on reducing unemployment. Most of Keating's statement focused on detailed proposals for doing this. But it also contained various science policy initiatives, including a proposal for an eight-year programme to support "major national research facilities".

Few details have been released about how the programme would work. But a spokesman for Peter Cook, the recently appointed minister for science, said the money would be used only to set up the centres.

Operating costs would have to be found by the centres themselves, or by the institution or department responsible for them.

Cook said his department had a list of proposals including a number from other departments. Outside proposals would also be accepted. The most advanced proposal is for a Nanotechnology Facility. Keating said the facility would build on the work of the Cooperative Research Centre for Molecular Engineering - recently created under a separate government programme - which was developing nanotechnology devices for the health-care, food and environment industries in Australia.

The second major initiative, the technology diffusion centres, will involve setting up demonstration sites of new technology so that business owners and executives can see the technology in action. The spokesman for Cook said the sites would help overcome the reluctance of businessmen to adopt new technology.

The CSIRO has been given an extra A $\$ 10$ million to help it work more closely with small and medium-sized enterprises, as well as A\$7 million to improve business access to advanced technologies. But it will suffer a $\$ 20$ million cut in its annual budget for the next three years.

Sources in CSIRO said the jobs lost would be initially in the administrative and support areas, and that several divisions (the basic operating units) would be cut into smaller research centres.

Mark Lawson

\section{French academy baffled by language rule}

Paris. The French Academy of Sciences last week accused the government of being out of touch with the research community, after the National Assembly had ignored repeated requests to exempt international scientific conferences from provisions of a bill on the use of the French language (see Nature 367, 304; 1994).

Last month, the academy published a public appeal, entitled "French science is in danger!", asking the government to exempt scientific congresses attended by a majority of non-French speakers from the requirement that French can be spoken. The bill, which was adopted by the National Assembly last week, also requires all written contributions (and the subsequent proceedings) of such conferences to include at least summaries in French.

Paul Germain, the permanent secretary of the academy, says that the bill would make it impossible for French organizations to hold international con- ferences in France. He says that it would be impractical to produce proceedings in French, and financial suicide to have to supply simultaneous translation.

But, in a further blow to the academy's campaign, the National Assembly also adopted an amendment requiring all research supported by public funds to be published in French. Germain says he is baffled by what this is intended to mean in practice, but adds that he is shocked that the government, despite its "good intentions", has "absolutely no idea" of how the scientific community works.

The academy says it will continue to fight the bill during its second reading in the Senate. The Centre National de la Recherche Scientifique for its part says that the defence of the French language depends mainly on having the quality of research and funds needed to attract foreign researchers - and their families - to France.

Declan Butler 